\title{
If Building Trust Is Important, How Do We Teach Novice Evaluators to Do It?
}

\author{
Bianca Montrosse-Moorhead \\ University of Connecticut
}

\begin{abstract}
Building trust with stakeholders is essential for conducting meaningful evaluation work. This practice note describes an instructional activity developed to help novice evaluators learn to build and maintain trust with stakeholders, and illuminates key pedagogical aspects to aid evaluation educators in using or adapting this learning activity. Relevant literature is reviewed before describing why trust is the focus, the learning context in which this activity was developed and enacted, and the learning activity itself. The practice note concludes with a discussion of four critical ingredients that are central to this learning activity and implications for evaluation teaching, learning, and research.
\end{abstract}

Keywords: evaluation education, interpersonal skills, novice evaluators, situational practice, trust

Résumé : Létablissement de liens de confiance avec les intervenants et intervenantes est essentiel pour qu'un travail d'évaluation soit significatif. Cette note sur la pratique décrit une activité pédagogique mise au point pour aider les évaluatrices et évaluateurs novices à apprendre à établir et à maintenir un lien de confiance avec les parties prenantes et souligne les composantes pédagogiques clés à considérer lors de l'utilisation ou de l'adaptation de cette activité d'apprentissage. La littérature pertinente est examinée avant de décrire les raisons pour lesquelles la confiance est au cour de la démarche, le contexte d'apprentissage dans le cadre duquel l'activité a été élaborée, et l'activité d'apprentissage elle-même. La note se termine par une discussion de quatre ingrédients essentiels à l'activité d’apprentissage et ce qui pourrait s'ensuivre pour l'enseignement, l'apprentissage et la recherche dans le domaine de l'évaluation.

Mots clés :formation en évaluation, compétences interpersonnelles, évaluatrices débutantes, évaluateurs débutants, pratique situationnelle, confiance

This practice note describes an instructional activity developed for helping novice evaluators learn to build and maintain trust with stakeholders, and illuminates key pedagogical aspects. I first review relevant literature on interpersonal skills and then describe the learning context in which this activity was developed and

Corresponding author: Bianca Montrosse-Moorhead, University of Connecticut, Department of Educational Psychology, 249 Glenbrook Road, Unit 3064, Storrs, CT, 06269;

bianca@uconn.edu 
enacted, reasons for the focus on trust, and the learning activity itself. The practice note concludes with implications for evaluation teaching, learning, and research.

\section{BRIEF LITERATURE REVIEW}

Evaluation is a social practice, meaning that human interactions and relationships are at its core. This is one reason why interpersonal skills in evaluation are important (King \& Stevahn, 2013; Kirkhart, 1995; Patton, 1978). Professional organizations such as the American Evaluation Association (AEA) and the Canadian Evaluation Society (CES) have sought to explicate what is included under the interpersonal skills umbrella. CES (2018), for example, defines interpersonal skills to include a focus on social and personal skills, communication, and the ability to interact effectively with all stakeholders. These interpersonal competency explications are based on a literature generated by scholars and practitioners with a collaborative (Cousins et al., 2019) or transformative orientation ${ }^{1}$ to evaluation practice (Cram, 2009; Hood et al., 2015; House \& Howe, 1999).

Interpersonal skills influence evaluation practice. Evaluation use (Acree \& Chouinard, 2019; Alkin \& King, 2017), the validity of evaluative inferences (Griffith \& Montrosse-Moorhead, 2014; Kirkhart, 2005), and the degree of cultural competence are all impacted by evaluators' interpersonal skills and the axiological assumptions evaluators bring to the work (Cram, 2009). Writings also call attention to the link between interpersonal skills and access to data, data quality, stakeholder resistance, and credibility (Donaldson et al., 2015). This work, for example, has shown that inappropriate (or no) use of interpersonal skills has led to stakeholder resistance to evaluation in general, and to refusal to participate in data-collection efforts.

While the importance of interpersonal skills is well established, more work must be done by evaluation educators. King and Stevahn (2013) note that evaluation educators have not drawn much from well-established social practice theories in psychology to inform how they support interpersonal skill development in future evaluators. Clinical psychology, for example, has long recognized and researched the importance of interpersonal skills to professional practice, and thus explicitly embeds their development within education programs (Grossman et al., 2009). And yet, consistent with King and Stevahn's claim, several research studies find that interpersonal skill development is least likely to be addressed in formal evaluator educator programs (Dewey et al., 2008; Galport \& Azzam, 2017; LaVelle, 2014). Echoing King and Stevahn, this practice note is rooted in a belief that connecting evaluation and clinical psychology teaching literature has the potential to inform interpersonal skill development in novice evaluators.

Moreover, there is little teaching literature focused on helping others develop these skills within evaluation. Preskill and Russ-Eft's (2016) book includes a few skill-building activities in the interpersonal skills domain, all centred narrowly on stakeholder resistance, evaluation politics, or communication. These one-shot activities, while a helpful starting point, do not provide the ongoing, purposeful, sustained learning needed to develop everything included under the interpersonal 
skills umbrella. This practice note provides an example of a more ongoing, purposeful, sustained learning activity.

\section{THE INSTRUCTIONAL ACTIVITY}

\section{Why focus on trust}

This activity is grounded in research, theory, and praxis emanating from clinical psychology on interpersonal skills (Horvath et al., 2011; Norcross, 2011). As noted in a comprehensive synthesis of clinical psychology literature, relationshipbuilding theories make a distinction between the process of relationship-building, using interpersonal skills such as empathy, goal consensus, collaboration, responsiveness, cultural competence, and the outcomes of appropriate relationshipbuilding skills, such as trust, ${ }^{2}$ and there is much empirical support for these distinctions (Norcross \& Lambert, 2011). The instructional activity described here assumes the same distinction, meaning it assumes trust in evaluation comes from appropriate use of interpersonal skills. Moreover, within clinical psychology, it is empirically documented that many means (processes) are effective at building trust (Norcross \& Lambert, 2011). This instructional activity also assumes the same distinction, meaning that it assumes there are many ways in which interpersonal skills can be used to build trust. This framing provides a common anchor for learning across novices, which is why trust is the focus, and also provides a way for interpersonal skill use to be contextually tailored.

\section{Learning context}

The context for this learning activity is a university-based program that prepares future evaluation scholars, educators, and practitioners through its Master's and doctoral programs. The program includes three courses devoted to the evaluation profession and to practice, with other courses focused on technical methods. This activity is situated within and embedded throughout the second course, a semester-long evaluation practice course, where students are required to navigate, for the first time, the dynamic interplay between theory, research, methods, and praxis with real stakeholders to produce an evaluation proposal.

\section{Learning activity description}

As the course instructor, to set the stage for the novice evaluators, I write a letter for the novice evaluator teams to share with potential partner organizations. It describes the class, its aims, and the expectations for the evaluators and partner organizations. It also purposefully calls attention to the audio recording of meetings and the sharing of these recordings-with whom, how, and for what purpose. Along with this letter I include an evaluation partnership agreement, in which an authorized representative of the partner organization acknowledges the general purposes of the collaboration and the particulars of involvement, including audio recording, verifies that questions have been answered satisfactorily, and agrees to 
move forward with the partnership. Only after this letter is signed does evaluation planning begin.

Each novice evaluator team has three to four self-selected students. Rather than prescribe a particular evaluation approach, teams work with partner organizations to determine the evaluation purpose, key questions, and the approach that best fits the evaluation context. Once an approach is selected, teams are required to use the seminal texts associated with that approach. Depending on the approach selected, discussion and use of interpersonal skills in service of trust-building varies significantly. To address this variability, students co-create instructional resources, namely audio recordings of meetings with various stakeholders within the partner organizations. Recordings can and often do include evaluation commissioners; program developers, managers, and staff; and those served by the program. These recordings are shared through a password-protected learning management system. Students are also required to read a chapter by Horvath et al. (2011), a comprehensive mixed-method review of trust research in clinical psychology. To facilitate student sense making from the chapter and set the stage for later work on trust building, students are asked to come to class prepared to discuss the following questions:

1. Horvath et al. discuss research on the process of developing trust. How does that research help us think about how to develop trust in evaluation?

2. What are the characteristics of trust building in evaluation? In other words, if you listened to an audio recording of a meeting between an evaluator and a stakeholder(s), what would you hear that would tell you trust was being built? Being hindered? Being resisted?

Throughout the semester, I devote class time to helping students learn to engage in trust-building practice. Each team shares several recordings from the semester. Prior to these class sessions, students are instructed to listen to recordings from other teams, to note instances of trust building, hindrance, or resistance, and to brainstorm potential suggestions to address trust hindrance and resistance. Later in the course and in instances in which the same people are on multiple audio recordings, students are instructed to write down their reflections on how trust has changed over time in this evaluation with this person or set of people. I listen to the recordings with the same prompts in mind, and contribute my observations and model reflective practice during class. This work is unscripted, meaning it changes year-to-year with the students, evaluation partners, and recordings.

Class sessions are a mix of small- and whole-group work. If time allows, I use a Think-Pair-Share cooperative discussion strategy in which students first work independently to answer prompts, and then small groups collaborate to discuss each prompt and generate talking points for a whole-group discussion (Lyman, 1981). Other times, I use the Jigsaw cooperative discussion strategy, where different groups focus on different prompts, with each group facilitating a whole-class discussion around their prompt and points to consider (Aronson \& Patnoe, 1997). 
Regardless of strategy, my instructional goals are the same: to help students recognize, in the moment, instances of trust building, hindrance, and resistance; and to build their capacity to build trust throughout an evaluation project.

\section{DISCUSSION}

Informed by evaluation and clinical psychology literature, I developed a reflective, ongoing, intentional learning activity to help novice evaluators with their trust-building practice. Four ingredients are critical here: (1) positioning trustbuilding as a core practice, (2) cultivating psychological safety in the classroom, (3) developing and asking meaningful questions, and (4) helping students identify aspects of trust-building practice.

\section{Critical ingredient 1: Trust-building as a core practice}

One key assumption embedded in this learning activity is that trust building in evaluation is a core practice. To make this explicit, students are introduced to the concept of core practices, or practices focused on helping novices develop their knowledge, skill, and professional identity in the process of learning to practice (Grossman et al., 2009). Next, students are presented with an argument for why trust building is a core practice. This includes the existence of a plethora of research outside of evaluation on the need to develop trust and how it results in positive outcomes (Horvath et al., 2011), and how trust is relevant in evaluation and plays an important role in the quality of the process and outcomes of an evaluation (Hood et al., 2015; Thomas \& Stevens, 2004). Building trust does not diminish integrity and complexity. Moreover, building trust occurs throughout the evaluation process and with high frequency, and there is no one-size-fits-all approach to building it. It is enacted across different contexts and evaluation approaches and can be taught to those new to evaluation. In this way, the process of learning how to build trust helps novices learn more about evaluation, evaluating, and evaluators.

\section{Critical ingredient 2: Cultivating psychological safety in the classroom}

Research has established that psychological safety, or belief about whether a particular context is safe for risk taking, is especially important for learning (Edmondson, 1999; Schein, 1993). Co-constructed course norms are one teaching strategy for creating a psychologically safe learning environment (Kegan \& Lahey, 2001). Examples of norms used in this course include "be honest with confusions," "share personal experiences to enrich learning," "lean into discomfort," and "recognize complexity."

\section{Critical ingredient 3: Developing and asking meaningful questions}

Extant research shows that question quality can make a difference in learning (Rosenshine, 2012). Questions posed have to elicit student thinking and help students build on that thinking in ways that extend learning for everyone (e.g., 
checking alternative interpretations or views, surfacing implicit assumptions). The questions posed in this learning activity are Socratic questions (Table 1), where the instructor adopts a novice mindset and assumes that knowledge is constructed through asking questions (Dillon, 1990). As is true for anyone using Socratic questioning as an instructional tool, the questions one asks are dependent on the discussion and educative materials being used.

\section{Critical ingredient 4: Identifying aspects of trust-building practice}

An important part of this learning activity is helping students understand what is meant by trust building and maintenance in evaluation. Because there is no empirical work within evaluation that focuses on trust building with the explicit aim of making it visible to novices, clinical psychology literature is used. This literature helps novices understand that trust building is both emergent and the result of mutual partnership and collaboration. Trust building is dynamic in the sense that it can, and often does, ebb and flow over time, both in terms of the quality of trust building and the aspects that influence it. It is thus always in process and never finished. It is framed, moreover, as something that can occur through multiple pathways, not through one single or specific approach. At a minimum, trust building requires three elements: a common understanding of purpose, shared agreement on processes and procedures in service of that purpose, and appropriate use of interpersonal skills.

\section{IMPLICATIONS FOR EVALUATOR EDUCATION TEACHING AND RESEARCH}

Several important pedagogical implications stem from this work and are important for those considering using or adapting this technique. One is that the

Table 1. Examples of Socratic questioning for trust-building practice

\begin{tabular}{|c|c|}
\hline Socratic question type & Example \\
\hline Clarifying & $\begin{array}{l}\text { How does this interaction relate to our discussion of trust } \\
\text { building in evaluation? }\end{array}$ \\
\hline Probing & $\begin{array}{l}\text { What could we assume instead about why resistance to this } \\
\text { aspect of the evaluation plan is occurring? }\end{array}$ \\
\hline Probing with evidence & $\begin{array}{l}\text { What do you think contributes to trust being built? Why? } \\
\text { What evidence is there that this is happening in this } \\
\text { situation? }\end{array}$ \\
\hline Perspective taking & $\begin{array}{l}\text { What is another way to interpret this conversation between } \\
\text { the evaluators and this stakeholder/these stakeholders? }\end{array}$ \\
\hline Consequential & $\begin{array}{l}\text { What are we assuming about trust building in this } \\
\text { circumstance? What is the consequence of this } \\
\text { assumption? }\end{array}$ \\
\hline Meta-questioning & $\begin{array}{l}\text { Why do you think I asked the question about who was } \\
\text { actively engaged in the conversation and who was not? }\end{array}$ \\
\hline
\end{tabular}


framing of trust building as a core evaluation practice is grounded in a sociocultural teaching and learning philosophy (Chaiklin \& Lave, 1996; Shulman, 2005). Education rooted in this perspective privileges understanding, skills, and knowledge and at the same time also recognizes that personal and professional identities, prior experiences, and context play a role in our practice. For this reason, learners are active participants in the learning process, and knowledge is co-constructed by novices and experts. The pedagogical skills required by an instructor for this learning activity necessarily differ from those required, for example, in a lecture-based environment. Two such examples are the ability for an instructor to cultivate psychological safety in the classroom and to develop and ask meaningful questions.

Psychological safety is important for this learning activity for several reasons. This learning activity is intentionally designed for teams to open up and share their practice. This is easier when things are going well and less so when they are not. Working with stakeholders for the first time presents the first real opportunity for novice evaluators to fail, and they need to be able to fail safely, fail early on, and learn how to use failure for learning. This can be especially difficult for students at the graduate level who have excelled academically. Moreover, it can be exacerbated by imposter syndrome, a persistent and untrue psychological thought process where one doubts one's own accomplishments and, because of this doubt, fears being found out as a "fraud." Prior research shows that imposter syndrome is widespread in graduate education, with higher rates among women, Black, Indigenous, Latinx and people of colour, and first-generation students (Parkman, 2016).

Co-constructed norms are one pedagogical tool that can be used to cultivate an atmosphere of psychological safety among students. Those new to co-creating course norms are directed to Kegan and Lahey (2001), which provides guidance and practical tools that can be adopted to facilitate this process. Kegan and Lahey note, for example, that the co-construction framing shifts the learning environment to one where everyone (not just the instructor) has the responsibility for upholding norms and calling attention to instances in which norms are not being authentically honoured. This shifting of responsibility to the collective also shifts students' interpersonal dynamics, "unfreezing" the things that get in the way of learning so that learning can occur.

Asking meaningful questions is also important for this learning activity. There are different questioning models to help guide instructors both within (Smith et al., 2015) and outside (Dillon, 1990) evaluation. This learning activity was designed using Socratic questioning, which instructionally requires that educators are willing and know how to assume a novice orientation, interpret in the moment what students understand and what they do not, be able to think quickly on their feet about what question makes sense instructionally, and tolerate uncertainty, since neither questions nor answers can be anticipated in advance. Prior education research on questioning practices has shown that questioning models are more difficult for those new to teaching or new to this questioning method because they do not yet have the practical knowledge about teaching and learning that comes from teaching itself (Lunenberg \& Korthagen, 2009). 
Socratic questioning, moreover, was intentionally selected for this learning activity because of its alignment with Argyris and Schön's (1996) theory of action framework, which suggest that our practices are composed of what individuals say (i.e., espoused beliefs and assumptions) and what they do (i.e., enacted beliefs and assumptions) and that there are often unnoticed discrepancies between the two that "freeze" learning. The result of unnoticed and unquestioned discrepancies is a focus solely on learning how to do something at an acceptable or optimal level. However, if these discrepancies can be illuminated and unpacked, it paves the way for practitioners to focus on learning why one would take a particular action, whether beliefs, assumptions, and action are in alignment, and what is getting in the way of learning and alignment. In sum, Socratic questions help facilitate students moving from know-how to know-why (Argyris \& Schön, 1996).

Reflection in action and reflection on action, which are part of Argyris and Schön's (1996) theory of action framework, do not come easy to novice evaluators (Smith et al., 2015). At the beginning, while students get the idea in theory, many have limited evaluation experiences from which to draw and little to no training in engaging in reflective practice. At the beginning of the semester, I thus rely quite a bit on my notes from the Horvath et al. (2011) chapter and the first round of audio recordings to facilitate the discussion and make visible aspects of trustbuilding practice (reflection on action). Doing so also models for students how to use these materials for the purpose of cultivating their own reflective practice. As the semester progresses and students become more comfortable sharing and better able to recognize various parts of trust building in practice, I use my notes to keep track of what has already been discussed, and what aspects from my notes, if any, need to be further unpacked. Moreover, this allows space to begin to have conversations about their in-the-moment learning (reflection in action) because students are more deliberate about what they are doing in practice and why, and are more fully able to articulate this. Research has shown that these kinds of meaningful reflection activities broaden students learning along the academic, social, moral, personal, and service dimensions of practice (Hatcher et al., 2004; Smith et al., 2015).

While these pedagogical implications are important, several future directions emanate from this work. It would be interesting to understand what other strategies beyond co-construction of norms could be used to create a culture of psychological safety in the classroom, or how different questioning methods influence the process and outcomes of student learning in this instructional activity. It is also possible that this pedagogical activity could be used beyond the classroom and adapted by practitioners wishing to engage in reflective practice, much like clinical psychologists do once they earn their degrees. What adaptations are needed to transfer this learning activity outside of the graduate learning environment?

To adapt a well-known quote-good evaluators are made, not born. And good evaluators are more than methodological technicians. To the extent that we believe both of these statements to be true, it means reframing evaluator education to focus on all aspects of good practice, and that includes trust-building practice. 


\section{NOTES}

1 Philosophically, these two orientations are rooted in the pragmatic or transformative paradigm, respectively, which has implications for their enactment in practice (Mertens \& Wilson, 2019).

2 The clinical term for trust is alliance, and as such it is the preferred term used in research studies, while trust is the preferred term in practitioner-oriented writing (Horvath et al., 2011).

\section{REFERENCES}

Acree, J., \& Chouinard, J. A. (2019). Exploring use and influence in culturally responsive approaches to evaluation: A review of the empirical literature. American Journal of Evaluation. https://doi.org/10.1177/1098214019879505

Alkin, M. C., \& King, J. A. (2017). Definitions of evaluation use and misuse, evaluation influence, and factors affecting use. American Journal of Evaluation, 38(3), 434-450. https://doi.org/10.1177/1098214017717015

Argyris, C., \& Schön, D. A. (1996). Organizational learning II: Theory, method and practice. Addison-Wesley.

Aronson, E., \& Patnoe, S. (1997). The jigsaw classroom (2nd ed.). Longman.

Canadian Evaluation Society (CES). (2018). Competencies for Canadian evaluators. https:// evaluationcanada.ca/competencies-canadian-evaluators

Chaiklin, S., \& Lave, J. (1996).Understanding practice: Perspectives on activity and context. Cambridge University Press.

Cousins, J. B., Shulha, L., Whitmore, E., Al Hudib, H., \& Gilbert, N. (2019). Situating evidence-based principles to guide practice in collaborative approaches to evaluation. In J. B. Cousins (Ed.), Global test drive of principles for collaborative approaches to evaluation. Sage.

Cram, F. (2009). Maintaining indigenous voices. In D. M. Mertens \& P. E. Ginsberg (Eds.), Handbook of social research ethics (pp. 308-322). Sage.

Dewey, J. D., Montrosse, B. E., Schroter, D. C., Sullins, C. D., \& Mattox, J. R. (2008). Evaluator competencies: What's taught versus what's sought. American Journal of Evaluation, 29(3), 268-287. https://doi.org/10.1177/1098214008321152

Dillon, J. (1990). The practice of questioning. Routledge.

Donaldson, S. I., Christie, C. A., \& Mark, M. M. (2015). Credible and actionable evidence: The foundation of rigorous and influential evaluations. Sage.

Edmondson, A. C. (1999). Psychological safety and learning behavior in work teams. Administrative Science Quarterly, 44(2), 350-383. https://doi.org/10.2307/2666999

Galport, N., \& Azzam, T. (2017). Evaluator training needs and competencies: A gap analysis. American Journal of Evaluation, 38(1), 80-100. https://doi.org/10.1177/109821401664 3183

Griffith, J. C., \& Montrosse-Moorhead, B. (2014). The value in validity. New Directions for Evaluation, 142, 17-30. 
Grossman, P., Compton, C., Igra, D., Ronfeldt, M., Shahan, E., \& Williamson, P. (2009). Teaching practice: A cross-professional perspective. Teachers College Record, 111, 2055-2100. https://www.tcrecord.org/Content.asp?ContentId=15018

Hatcher, J., Bringle, R., \& Muthiah, R. (2004). Designing effective reflection: What matters to service-learning. Michigan Journal of Community Service Learning, 4, 22-29.

Hood, S., Hopson, R., \& Kirkhart, K. (2015). Culturally responsive evaluation: Theory, practice, and future implications. In K. Newcomer, H. Hatry, \& J. Wholey (Eds.), Handbook of practical program evaluation (pp. 281-317) Jossey-Bass.

Horvath, A. O., Del Re, A. C., Fluckiger, C., \& Symonds, D. (2011). Alliance in individual psychotherapy. In L. S. Greenberg \& W. M. Pinsof (Eds.), The psychotherapeutic process: A research handbook (pp. 529-556). Guilford.

House, E. R., \& Howe, K. R. (1999). Values in evaluation and social research. Sage.

Kegan, R., \& Lahey, L. L. (2001). How the way we talk can change the way we work: Seven languages for transformation (1st ed.). John Wiley \& Sons.

King, J. A., \& Stevahn, L. (2013). Interactive evaluation practice: Mastering the interpersonal dynamics of program evaluation. Sage.

Kirkhart, K. E. (1995). Seeking multicultural validity: A postcard from the road. Evaluation Practice, 16(1), 1-12. https://doi.org/10.1016/0886-1633(95)90002-0

Kirkhart, K. (2005). Through a cultural lens: Reflections on validity and theory in evaluation. In S. Hood, R. Hopson, \& H. Frierson (Eds.), The role of culture and cultural context (pp. 21-38). Information Age Publishing.

LaVelle, J. M. (2014). An examination of evaluation education programs and evaluator skills across the world (Unpublished doctoral dissertation). The Claremont Graduate University.

Lunenberg, M., \& Korthagen, F. (2009). Experience, theory, and practical wisdom in teaching and teacher education. Teachers and Teaching, 15(2), 225-240. https://doi. org/10.1080/13540600902875316

Lyman, F. (1981). The responsive classroom discussion: The inclusion of all students. In A. Anderson (Ed.), Mainstreaming digest (pp. 109-113). University of Maryland Press.

Mertens, D. M., \& Wilson, A. T. (2019). Program evaluation theory and practice (2nd ed.). Guilford.

Norcross, J. C. (Ed.). (2011). Psychotherapy relationships that work: Evidence-based responsiveness (2nd ed.). Oxford University Press.

Norcross, J. C., \& Lambert, M. L. (2011). Evidence-based therapy relationships. In J. C. Norcross (Ed.), Psychotherapy relationships that work: Evidence-based responsiveness (pp. 3-21). Oxford University Press.

Parkman, A. W. (2016). The imposter phenomenon in higher education: Incidence and impact. Journal of Higher Education Theory and Practice, 16, 51-60. https://doi. org/10.33423/jhetp.v16i1.1936

Patton, M. Q. (1978). Utilization-focused evaluation (1st ed.). Sage.

Preskill, H., \& Russ-Eft, D. F. (2016). Building evaluation capacity: Activities for teaching and training. Sage. 
Rosenshine, B. (2012). Principles of instruction: Research-based strategies that all teachers should know. American Educator, 36, 12-19. https://www.aft.org/sites/default/files/ periodicals/Rosenshine.pdf

Schein, E. H. (1993). On dialogue, culture, and organizational learning. Organizational Dynamics, 22(2), 40-51. https://doi.org/10.1016/0090-2616(93)90052-3

Shulman, L. S. (2005). Signature pedagogies in the professions. Daedalus, 134(3), 52-59. https://doi.org/10.1162/0011526054622015

Smith, T. L., Barlow, P. B., Peters, J. M., \& Skolits, G. J. (2015). Demystifying reflective practice: Using the DATA model to enhance evaluators' professional activities. Evaluation and Program Planning, 52, 142-147. https://doi.org/10.1016/j.evalprogplan.2015.04.004

Thomas, V. G., \& Stevens, F. I. (2004). Co-constructing a contextually responsive evaluation framework: The talent development model of reform. New Directions for Evaluation, $101,1-93$.

\section{AUTHOR INFORMATION}

Bianca Montrosse-Moorhead is an associate professor of evaluation at the University of Connecticut, where she trains future practitioners and scholars. Her research centres on evaluation education, methodology, and practice. 